\title{
Multipurpose Bench as an Alternative Infrastructure of Transportation
}

\author{
Sandi Yudha B.Z ${ }^{1}$, Ihsan ${ }^{2}$, Nuzuli Fitriadi ${ }^{3}$ \\ 1) Department of Mechatronics Engineering, Aceh Polytechnic - Banda Aceh, Indonesia \\ 2, 3) Department of Mechanical Engineering, South Aceh Polytechnic - Tapaktuan, Indonesia \\ Email : sandiybz@politeknikaceh.ac.id
}

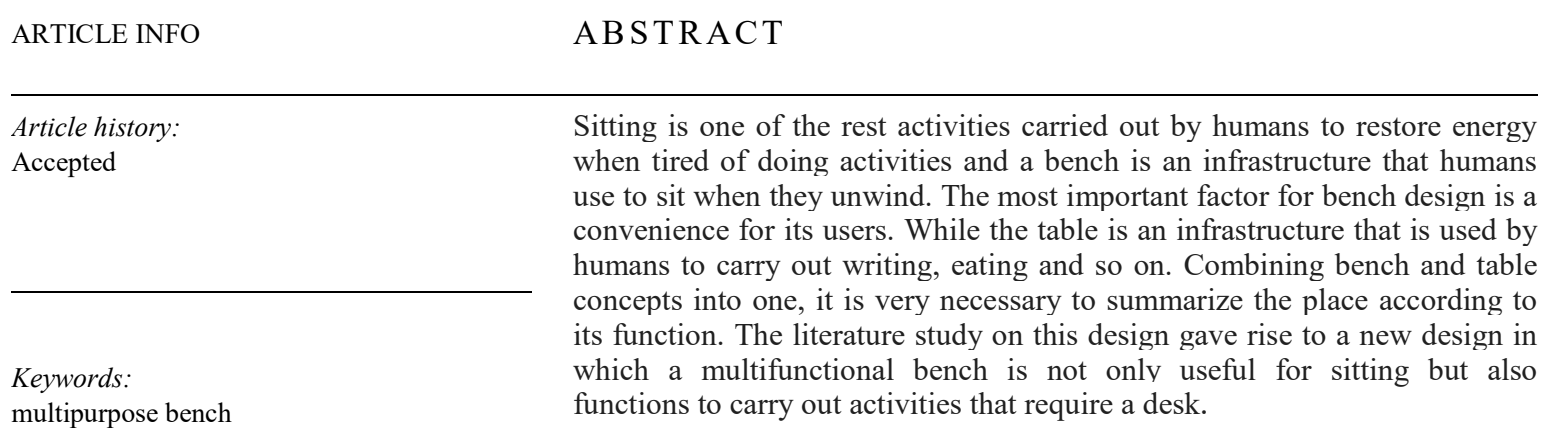

transportation mean

design alternatives

Copyright (C) 2019 Politeknik Aceh Selatan. All rights reserved.

\section{Introduction}

Humans use a bench to rest when they are tired in their activities. While the table is used to put food, drinks or work equipment when humans work.

Some studies are for the design of benches and tables. Nader Mahmoudia and friends [1], conducted research on workbenches that were comfortable to use. Ashutosh Bijalwan and colleagues [2] conducted a study by designing and analyzing the Stool using the finite element method. Mr. D. G. Gawande and Dr. R. E. Thombre [3] conducted a study by analyzing the maximum stress that occurred on the bench using the finite element method. Nasr Al-Hinai and friends [4] conducted a study by analyzing the convenience of a folding bench for students in the classroom teaching and learning environment.

Research on benches or tables done above is not done on long benches and tables (used by more than one person simultaneously). Therefore, a study was conducted to design a multipurpose bench that was used by more than one person together.

\section{Related Studies}

Every day, humans spend a lot of time sitting when they eat, drink, study, work, drive and so on.

Humans need rest to restore energy due to fatigue because of the activities that have been done. One of the rest activities is sitting. The infrastructure used to carry out this activity is a bench.

Comfort when sitting is very necessary with consideration of size is the average posture and body shape of every human being. Figure 1 describes several aspects that determine the dimensions of the bench to be analyzed. 


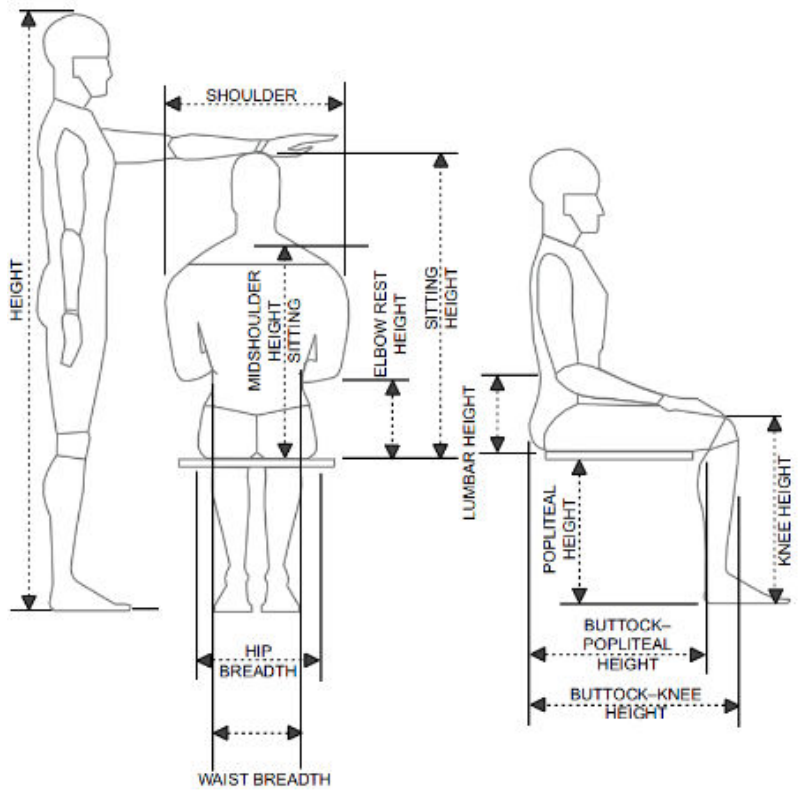

Fig 1. Dimension of the human body

Based on the convenience of the bench design can be seen in Table 1:

Table 1 Standards No. ANSI/HFES 100-2007 and BSR/HFES 100-2002 with recommendations for a comfortable bench design

\begin{tabular}{|c|c|c|c|c|}
\hline \multirow{3}{*}{ Parameter } & \multicolumn{2}{|c|}{ ANSI/HFES 100-2007 } & \multicolumn{2}{|c|}{ BSR/HFES 100-2002 } \\
\hline & & & Requiremen & \\
\hline & Requirement & Recommendation & $\mathrm{t}$ & Recommendation \\
\hline Seat height (adjustable) & $38-56 \mathrm{~cm}$ & & $38-56 \mathrm{~cm}$ & \\
\hline Seat pan tilt (backward) & $\begin{array}{c}4^{0}-6^{0} \\
90^{0}-105^{0} \text { or } 90^{0}-\end{array}$ & & $\leq 6^{0}$ & \\
\hline $\begin{array}{l}\text { Seat pan-backrest angle } \\
\text { Seat pan-backrest recline }\end{array}$ & $120^{\circ}$ & & $\geq 90^{\circ}$ & \\
\hline a & $0^{0}-15^{0}$ & & $0^{0}-15^{0}$ & \\
\hline Seat pan depth & $\leq 43 \mathrm{~cm}$ & & & $\leq 43 \mathrm{~cm}$ \\
\hline Seat pan width & $\leq 45 \mathrm{~cm}$ & & & $\geq 45 \mathrm{~cm}$ \\
\hline Backrest width & & $\geq 36 \mathrm{~cm}$ & & $\geq 36 \mathrm{~cm}$ \\
\hline Backrest height & & $\begin{aligned} \geq & 45 \mathrm{~cm} \text { above } \mathrm{CSH} \\
& 15-25 \mathrm{~cm} \text { above }\end{aligned}$ & & $\begin{aligned} \geq & 45 \mathrm{~cm} \text { above } \mathrm{CSH} \\
& 15-25 \mathrm{~cm} \text { above }\end{aligned}$ \\
\hline Lumbar support (adjustable) & & $\mathrm{CSH}$ & & $\mathrm{CSH}$ \\
\hline Armrest height (fixed) & & $17-27 \mathrm{~cm}$ & & $17-27 \mathrm{~cm}$ \\
\hline Armrest height (adjustable) & & $18-27 \mathrm{~cm}$ & & $18-27 \mathrm{~cm}$ \\
\hline Armrest span & & $46 \mathrm{~cm}$ & & \\
\hline
\end{tabular}

Notes. $\mathrm{a}=$ recommended range in both standards: $0^{0}-30^{0}\left(<30^{0}\right.$ if head rest necessary); $\mathrm{CSH}=$ compressed seat height

Humans in writing activities, writing, eating, drinking and others, need a table as a means of supporting their activities.

The comfort aspect of the table is very necessary, because if it is not in accordance with the posture of the human body, activities involving the table as an infrastructure will cause injury to the human body.

The size of the table for writing, eating, drinking, and other activities is taken based on the height of the table on the folding table as shown in Figure 2. 

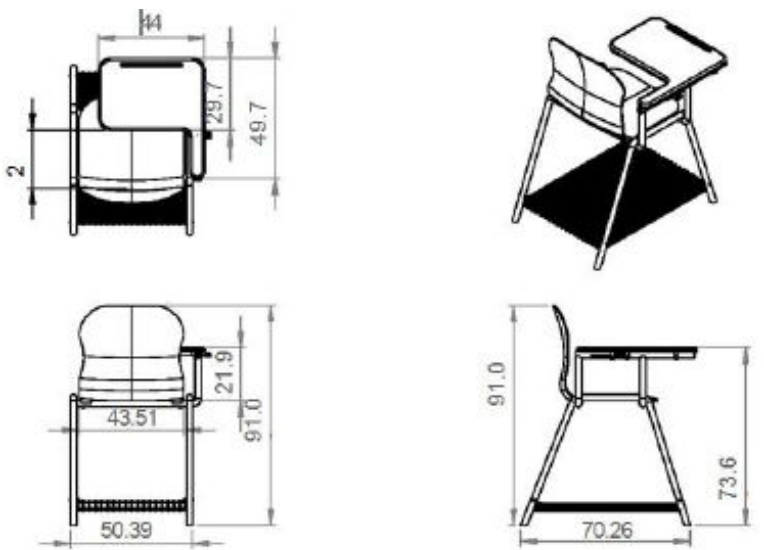

Fig 2. Bench and Table Size in folding bench design $(\mathrm{cm})$

\section{Multipurpose Bench Design}

This multipurpose bench design is made using a CAD application as shown in figure 3 to figure 4 . This bench can be used as a bench for the capacity of 1-3 people as shown in figure 3 . This bench can also be used with a combination of benches and tables as shown in picture 4 .

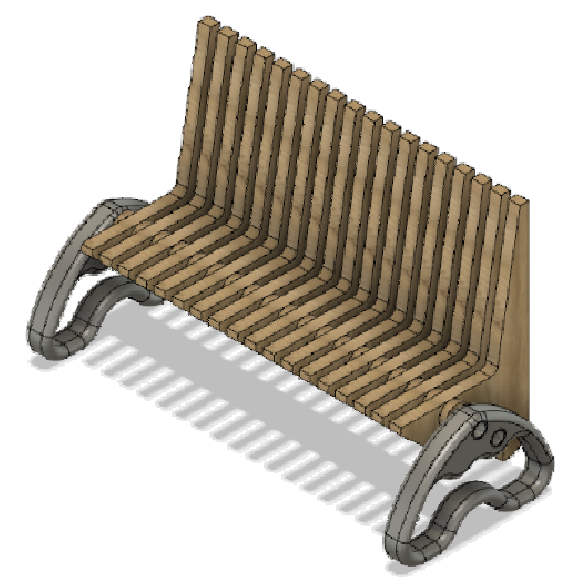

Fig 3. Multipurpose bench functioned as a bench

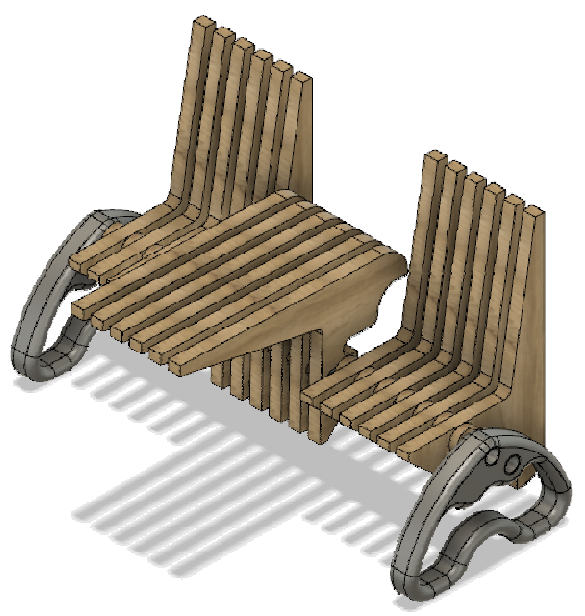

Fig 4. Multipurpose bench are used as benches and tables 

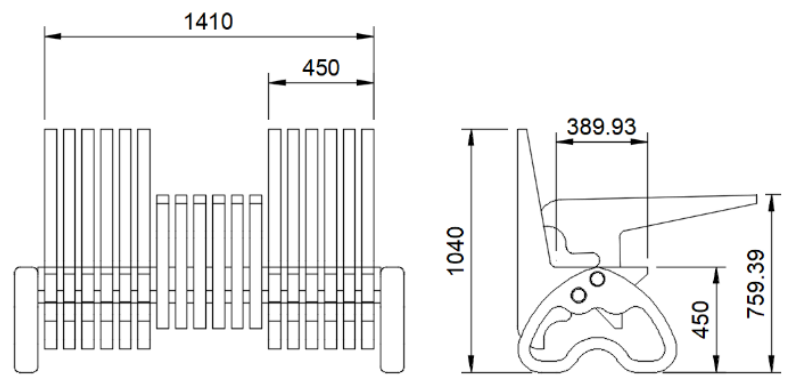

Fig 5. Dimension of multipurpose bench (mm)

\section{Results and Discussion}

Multipurpose bench design can be used 1-3 people, where the bench can also function as a table to put objects on it.

Based on Table 1, the width of the bench for 1 person is $<45 \mathrm{~cm}$. Whereas for bench height for seats is between $36-56 \mathrm{~cm}$. A table that serves as a place to put hands when relaxed or put something like food, drinks, bags, etc. on the design is as high as $+76 \mathrm{~cm}$ in accordance with the research conducted by Nasr Al-Hinai and friends [4].

\section{Conclusion}

At the end of this study, a multipurpose bench that also functions as a table and can be used by 1-3 people can be an alternative to transportation infrastructure. In the end, a multipurpose bench that can function as a table can be used by 1-3 people.

\section{Acknowledgment}

Thank you, the researcher conveyed to the Head of the Aceh Polytechnic Mechatronics Study Program and Head of the Aceh Polytechnic Mechatronics Workshop, who had lent a laboratory to conduct research.

\section{References}

[1] Nader Mahmoudia \& Majid Bazrafshana. 2015, A Carpet-Weaver's Chair Based on Anthropometric Data. International Journal of Occupational Safety and Ergonomics (JOSE), Vol 19: $543-550$.

[2] Ashutosh Bijalwan \& Anadi Misra. 2016. Design and Structural Analysis of Flexible Wearable Chair Using Finite Element Method. Open Journal of Applied Sciences, 2016, 6: $465-477$.

[3] Mr.D.G.Gawande \& Dr.R.E.Thombre. 2017. Stress Analysis On Chair Frame. International Research Journal of Engineering and Technology (IRJET): 1685 - 1689.

[4] Nasr Al-Hinai, Mahmood Al-Kindi, Ahm Shamsuzzoha. 2018. An Ergonomic Student Chair Design and Engineering for Classroom Environment. International Jpurnal of Mechanical Engineering and Robotics Research Vol. 7, No.5: $534-543$. 